\title{
Educação em saúde: uma análise do impacto do projeto jovem doutor em escolas públicas
}

\author{
Health education on speech-language pathology and \\ audiology in public schools
}

\author{
Wanderléia Quinhoneiro Blasca', Daniela Dias Gomide², \\ Izabel Cristina Rossi Landro ${ }^{3}$, Maria Thereza Raab Forastieri Piccino ${ }^{4}$, Luciana Paula Maximino 5 \\ 'Faculdade de Odontologia de Bauru - USP, FOB-USP. Bauru, São Paulo, Brasil. ORCID: 0000-0002-2634-0607.wandablasca@usp.br \\ ${ }^{2}$ Autora para correspondência. Faculdade de Odontologia de Bauru - USP, FOB-USP. Bauru, São Paulo, Brasil. \\ ORCID: 000-0003-4806-3679. danielagomide@hotmail.com \\ ${ }^{3}$ Faculdade de Odontologia de Bauru - USP, FOB-USP. Bauru, São Paulo, Brasil. ORCID: 0000-0002-2962-8171. rossilandro@uol.com.br \\ ${ }^{4}$ Universidade de São Paulo. São Paulo, São Paulo, Brasil. ORCID: 0000-0002-1912-0083. tecapiccino@usp.br \\ ${ }^{5}$ Faculdade de Odontologia de Bauru - USP, FOB-USP. Bauru, São Paulo, Brasil. ORCID: 0000-0003-3949-4426. lumaximino@uol.com.br
}

Resumo I O presente estudo analisa dados que envolvem crescimento de nível de conhecimento de 90 alunos de 9 escolas públicas realizados pelo Projeto Jovem Doutor. Os dados analisados são referentes à avaliação subjetiva motivacional de cursos a distância e mensuração de mudança de comportamentos sociais após a aplicação do Projeto. Nestes Projetos, jovens de ensino Fundamental II e Médio são instruídos sobre diferentes temas da área da saúde e submetidos a instrumento de avaliação para cômputo do programa e analise de impacto de tal Programa em atitudes sociais de escolares. Este artigo buscou demonstrar o caráter educativo essencial de Programas de Educação em Saúde nas escolas, após sua obrigatoriedade como tema transversal. Para tanto a analise se limitou à temas na área de fonoaudiologia e trabalhos desenvolvidos em tal curso na cidade de Bauru e Manaus.

PALAVRAS-CHAVE: Educação em Saúde. Desenvolvimento da Comunidade. Fonoaudiologia.

\begin{abstract}
The present study analyzes data on the training of students from 9 public schools carried out by the Young Doctor Project. In this project, youngsters from Primary and Secondary Education are educated about different health topics and submitted to an evaluation tool to measure the program. This article sought to demonstrate the essential educational character of Health Education Programs in schools, after its mandatory as a transversal theme. Therefore, the analysis was limited to topics in the area of speech therapy and work developed in such a course in the city of Bauru.
\end{abstract}

KEYWORDS: Health Education. Community development. Speech Therapy. 


\section{Introdução}

O Brasil é um país que apresenta crescimento econômico superior ao seu desenvolvimento, considerando que estes conceitos se diferenciam em dados quantitativos e qualitativos respectivamente. Essa característica gera grupos menos favorecidos que sofrem as consequências da desigualdade econômica e social'. Tal situação é agravada quando os indivíduos destes grupos possuem pouca oportunidade de ascensão social. Em uma sociedade de consumo e informacionalista onde a fluidez e rapidez são características marcantes, a necessidade de capacitação profissional é maior e os grupos sociais menos favorecidos são os mais afetados em virtude de sua condição de marginalização social. Diante desta realidade os valores expressos na escola podem ser únicos na vida do indivíduo. Assim, a escola assume um papel decisivo no desenvolvimento destes grupos podendo resgatar indivíduos e direciona-los à novos hábitos e costumes através de trabalhos contínuos e sistemáticos, que podem se iniciar na pré-escola estendendo-se ao ensino médio. Considerando este contexto, a saúde, direito universal do ser humano, muitas vezes se torna preocupação da comunidade escolar, atribuindo-lhe assim papel decisivo no encaminhamento do indiviudo à um centro de Saúde pública ou atuando na sua promoção e prevenção.

A saúde pública é uma área muito afetada por esta situação econômica desigual. Embora o Brasil possua um sistema de saúde pública, cujos elementos integrantes englobem atividades de promoção, proteção e recuperação da saúde, o SUS (Sistema Único de Saúde) não atinge toda a população brasileira. Um documento publicado em 2012 pela Organização Pan-Americana da Saúde e pela Organização Mundial da Saúde (OPAS/OMS) aponta que do SUS depende a saúde de $75 \%$ da população do Brasil. O relatório aponta que um dos desafios do SUS é "seguir garantindo, com recursos públicos, o acesso a serviços e tecnologia em saúde para toda a população". Por isso, as regiões do país são mais ou menos favorecidas impactando na qualidade do serviço e excluindo grupos ${ }^{2}$. Diante deste quadro, a educação para a promoção da saúde nas escolas se torna ainda mais importante.
Ainda que educar para a saúde seja responsabilidade de diferentes segmentos, a escola pode se transformar em um espaço de promoção da saúde por meio da criação de programas de educação em saúde direcionados. $O$ professor pode ser o maior responsável no processo de educação em saúde, colaborando para o desenvolvimento do pensamento crítico e estimulando a criança a mudanças de comportamento, que podem ser favoráveis à saúde ${ }^{3}$.

Essa relação entre escola e ações de saúde não é recente. É a partir do final do século XIX e, principalmente, na primeira metade do $X X$, que a saúde adentra o ambiente escolar brasileiro de modo a regulamentar e reger algumas ações dentro da escola. O tema saúde passou a ser trabalhado no ambiente escolar com o objetivo de alcançar as mínimas condições sanitárias que possibilitassem à exportação agrícola. Nesta conjuntura, a escola passa a ser vista como um ambiente promissor para disseminação de ações sanitárias e de higiene, pretendidas pelo governo ${ }^{4}$. Contudo, apenas na Lei de Diretrizes e Bases da Educação de 1971 (LDB/71) que o tema saúde passou a ser garantido no ambiente escolar. Com o Parecer 2.264/1974 os Programas de Saúde foram regulamentados a passaram a ser realizados na escola com o intuito de romper com a forma de abordagem da educação em saúde herdada do século anterior. Portanto, a principal inovação do documento foi a forma de tratamento do tema saúde, pois este passa a ser aplicado de maneira interdisciplinar. Contudo, as intenções sanitaristas e higienistas ainda se mantêm forte e os Programas de Saúde acabaram criando mais uma disciplina escolar ${ }^{b}$. Neste momento histórico o desenvolvimento da educação em saúde ficou sob responsabilidade da disciplina de ciências ${ }^{6,4}$.

É somente com a criação dos Parâmetros Curriculares Nacionais do Ensino Fundamental de 19981, que o tema saúde torna a ser assegurado no ambiente escolar. Segundo o Parâmetro Curricular Nacional, o tema saúde deverá ser abordado em ambiente escolar de maneira transversal, assim descrito:

É preciso educar para a saúde levando em conta todos os aspectos envolvidos na formação de hábitos e atitudes que acontecem no dia-a-dia da escola. Por esta razão, a educação para a Saúde será tratada como tema transversal, permeando todas as áreas que compõem o currículo escolar'. 
Importante destacar a importância de programas de saúde inseridos nesta proposta de transversalidade, pois eles possibilitam que estudantes e profissionais da área específica, neste caso da saúde, façam a abordagem necessária para que haja realmente a educação em saúde ${ }^{6}$.

Os programas destinados à Educação em Saúde podem, por meio de seu perfil especialista, pensar estratégias educacionais para cada público, ampliando a sensibilização e educação. $O$ uso de tecnologias e metodologias ativas também incrementa sua construção.

Estratégias de Educação em Saúde baseadas na tecnologia da informação e comunicação, transferindo informações de saúde entre locais distantes, motivam a mudança de comportamento para hábitos mais adequados e possibilitam envolver um maior número de pessoas.

Assim, neste contexto, a educação em saúde dentro das escolas dispõe da Teleducacão Interativa, que utiliza recursos tecnológicos possibilitando o despertar do interesse objetivando a facilidade do aprendizado. Tais recursos podem ser usados pelo educador da forma mais conveniente, de maneira presencial ou à distância, promovendo dinamismo na aquisição do conhecimento de diversos temas em saúde. As ferramentas tecnológicas são usadas na elaboração de um modelo educacional primando pela criatividade e direcionamento da linguagem mais adequada para o público em questão. Com esse propósito, justifica-se a aplicação da Teleducação Interativa em comunidades carentes, pois se trata de uma proposta de comunicação dinâmica, promovendo inclusão digital e abrindo as portas ao jovem de baixa renda à realidade do mundo universitário, da pesquisa e do desenvolvimento humano.

Nesse cenário é importante ressaltar o Projeto Jovem Doutor. Desenvolvido em 2007 pelo Prof. Chao Lung Wen, coordenador da Disciplina de Telemedicina da Faculdade de Medicina da Universidade de São Paulo, o projeto utiliza estratégias de Teleducação Interativa e o desenvolvimento de objetos de aprendizagem em temas relacionados a saúde ${ }^{7}$.

\section{O projeto Jovem Doutor}

O Projeto Jovem Doutor tem como propósito, incentivar os estudantes do ensino fundamental, médio e superior a realizarem trabalhos cooperados, que promovam a saúde e a melhora da qualidade de vida de comunidades necessitadas. Trata-se de uma oportunidade dada aos jovens do exercício da cidadania. O jovem, intitulado "Jovem Doutor", depois de receber a capacitação para determinado tema, pelos professores e profissionais da área, poderão ajudar a comunidade em que estão inseridos, transmitindo o conhecimento que adquiriram em sala de aula. O Projeto assume um compromisso com o desenvolvimento social, pois após adquirir conceitos na área de saúde, o jovem se conscientiza da necessidade de passar as informações para seus colegas, familiares e comunidade ${ }^{8}$.

O Projeto teve início na cidade de Tatuí, interior de São Paulo e desde então a cada ano forma-se uma nova turma para dar seguimento ao projeto. Estendido às cidades de Bauru, São Paulo (no estado de São Paulo), Parintins e Manaus (no estado do Amazonas), tendo considerável abrangência, busca desenvolvimento social, de acordo com as necessidades identificadas nos locais em que atua, por esta razão os temas são escolhidos após uma análise da região?

Em Bauru o projeto é atuante desde 2008, no departamento de Fonoaudiologia, sob a coordenação da profa. Dra. Wanderleia Quinhoneiro Blasca, docente Universidade de São Paulo. Foram realizados trabalhos junto aos alunos da Liga de Telessaúde de Fonoaudiologia e Odontologia e do Programa de Educação Tutorial da Faculdade de Odontologia de Bauru nos anos de 2008 e 2009, com o objetivo de criar uma "rede de aprendizagem colaborativa" entre os alunos do ensino fundamental e médio, a respeito das temáticas Saúde Auditiva e Saúde Vocal ${ }^{10,11}$.

O objetivo foi trabalhar com temas voltados para os cuidados com a audição e voz. Neste artigo serão analisados especificamente os trabalhos de mestrado e doutorado, desenvolvidos neste departamento e seu impacto nas escolas desde sua implantação. 
Logo, além da preocupação com a saúde auditiva, a necessidade da inclusão social de alunos com Síndromes Genéticas e deformidades teve destaque. Entre os temas desenvolvidos para a capacitação dos alunos estão Saúde Auditiva, Saúde Vocal, Síndrome Genética, Deformidades de orelha, SAHOS (Síndrome da Apneia/ Hipopnéia do Sono) e Prevenção na Saúde Auditivo $8,11,12,13,14,15$.

\section{Objetivo}

Portanto, este artigo objetiva avaliar o impacto da aplicação do Projeto Jovem Doutor realizado em escolas públicas com diferentes temas em em saúde

\section{Metodologia para avaliação do programa}

Trata-se de uma revisão de literatura envolvendo a aplicação Projeto Jovem Doutor desenvolvidos no departamento de fonoaudiologia da Faculdade de Odentologia de Bauru-Universidade de São Paulo, com o propósito de mensuração das atividades realizadas, os projetos foram examinados por meio da aplicação de diferentes instrumentos seguindo o objetivo proposto por cada estudo. Os questionários utilizados nas pesquisas avaliadas, foram $\circ$ Questionário Situação Problema (QSP), para analisar o crescimento do nível de conhecimento, Ficha de Pesquisa Motivacional (FPM), para avaliação subjetiva motivacional de cursos e programas que envolvam a Educação a Distância, Escala Lickert de atitudes sociais em relação à inclusão (ELASI) ${ }^{16}$, utilizada para mensurar atitudes sociais dos alunos frente ao processo de inclusão.

levantamento e explicação de cada meio de transmissão desenvolvido são relevantes, uma vez que são métodos eficazes de disseminação da infor- mação considerando seus resultados efetivos. Assim, dentro de cada projeto foram organizadas feiras de ciências, palestras, página em rede sociais, Blogs, aulas expositivas, teatro de fantoches, apresentação de vídeos e feiras culturais. Ressaltando que todas essas ferramentas foram produzidas e aplicadas pelos Jovens Doutores, ou seja, alunos das escolas públicas, que demonstraram interesse sobre o tema exposto e foram capacitados para transmitir os conhecimentos em saúde para o restante da escola, funcionários e comunidade $8,11,12,13,14,15$.

Em todos os projetos avaliados, tais estratégias ficaram disponíveis durante uma semana em áreas comuns das escolas, o que possibilitou a disseminação do conhecimento aos alunos, professores, funcionários. Foram convidados para participar destas atividades amigos da comunidade e familiares, visando abranger maiores números de pessoas.

Ao todo, as intervenções foram realizadas em 9 escolas públicas, sendo 7 na cidade de Bauru, interior do Estado de São Paulo e 2 na cidade de Manaus, capital do estado do Amazonas, envolvendo a capacitação de 90 alunos do ensino fundamental. As 9 escolas envolvidas possuem 9.071 alunos distribuídos nos períodos de funcionamento, 133 professores e 562 funcionários.

Os dados apresentados pelas escolas 1 e 2 referem-se a dois trabalhos de dissertações de mestrado $^{8,12}$ dados da escola 3, apresentam o trabalho realizado em uma tese de doutorado ${ }^{14}$. Já os dados apresentados pela escola 4, 5, 6 e $7^{13}$, referem-se a mesma dissertação de mestrado, os dados apresentados pelas escolas 8 e 9 foram realizados em dissertações de mestrado diferentes ${ }^{14,15}$.

O quadro 1 apresenta um panorama das escolas onde os trabalhos foram aplicados, quanto a localização, ao número de alunos, professores e funcionários: 
Quadro 1. Panorama das escolas onde os trabalhos foram aplicados

\begin{tabular}{|c|c|c|c|c|}
\hline $\begin{array}{c}\text { Referência da } \\
\text { Escola }\end{array}$ & Cidade & $\begin{array}{c}\text { Total de } \\
\text { Alunos }\end{array}$ & $\begin{array}{c}\text { Total de } \\
\text { professores }\end{array}$ & $\begin{array}{c}\text { Total de } \\
\text { funcionários }\end{array}$ \\
\hline Escola 1 & Bauru & 810 & 10 & 50 \\
\hline Escola 2 & Bauru & 978 & 21 & 59 \\
\hline Escola 3 & Manaus & 1800 & 12 & 55 \\
\hline Escola 4 & Bauru & 795 & 16 & 61 \\
\hline Escola 5 & Bauru & 786 & 15 & 73 \\
\hline Escola 6 & Bauru & 1245 & 14 & 57 \\
\hline Escola 7 & Bauru & 779 & 11 & 56 \\
\hline Escola 8 & Bauru & 939 & 17 & 74 \\
\hline Escola 9 & Bauru & 939 & 971 & 17 \\
\hline
\end{tabular}

\section{Programa de capacitação}

Dentro das escolas públicas, que participaram do Projeto, foram capacitados 90 jovens pela dinâmica do Projeto Jovem Doutor utilizando a Teleducação Interativa como recurso pedagógico 17 , conforme mostra 0 quadro 2:

Quadro 2. Panorama dos alunos capacitados pelo Projeto Jovem Doutor

\begin{tabular}{|c|c|c|}
\hline $\begin{array}{c}\text { Referência da } \\
\text { Escola }\end{array}$ & $\begin{array}{c}\text { Grau de } \\
\text { Escolaridade }\end{array}$ & $\begin{array}{c}\text { Alunos } \\
\text { Capacitados }\end{array}$ \\
\hline Escola 1 & $9^{\circ}$ ano & 9 \\
\hline Escola 2 & $8^{\circ}$ ano & 18 \\
\hline Escola 3 & $9^{\circ}$ ano & 12 \\
\hline Escola 4 & $9^{\circ}$ ano & 13 \\
\hline Escola 5 & $9^{\circ}$ ano & 05 \\
\hline Escola 6 & $9^{\circ}$ ano & 11 \\
\hline Escola 7 & $9^{\circ}$ ano & 09 \\
\hline Escola 8 & $8^{\circ}$ ano & 05 \\
\hline Escola 9 & $7^{\circ}$ ano & 08 \\
\hline Total & & 90 \\
\hline
\end{tabular}




\section{Ambiente virtual}

Nessa etapa, os jovens envolvidos nos estudos, foram cadastrados em uma plataforma de acesso disponibilizada pela faculdade. As atividades propostas e disponibilizadas no Ambiente Virtual de Aprendizado são explicadas aos jovens pelos pesquisadores para facilitar o acesso.

Nos trabalhos descritos neste artigo, os conteúdos foram inseridos no Cybertutor ${ }^{18}$. O Cybertutor ou tutor eletrônico na web é uma ferramenta de ensino desenvolvida pela Disciplina de Telemedicina da Faculdade de Medicina da Universidade de São Paulo DTM/FMUSP, caracterizada como um instrumento de Teleducação Interativa. Esta ferramenta disponibiliza o curso em um ambiente virtual de aprendizagem, permitindo o aprendizado via internet. Os tutores acompanharam o desenvolvimento dos alunos, possibilitando a aproximação entre eles. Os cursos disponibilizados na plataforma foram preparados com base na literatura pelos alunos de graduação e pós-graduação da Faculdade de Odontologia de Bauru- FOB e pelo Hospital de Reabilitação de Anomalias Craniofaciais- Universidade de São Paulo com uso de figuras, vídeos, animações e links com Websites. Mecanismos de incentivo são elaborados, onde o aluno passa por estágios de níveis de conhecimento respondendo a questionários, onde somente com cem por cento de acertos podem passar para um nível mais elevado. Finalizando o curso no prazo estipulado, os jovens receberam premiações elaboradas de modo específico em cada trabalho ${ }^{19}$.

No ambiente virtual também são disponibilizadas ferramentas assíncronas para estimular os alunos a discussão sobre os conteúdos aprendidos. Fóruns de discussão são oferecidos após o cadastro do aluno na plataforma. Tal ferramenta auxilia na mensuração de interesse e participação dos alunos, além de garantir o real aprendizado.
Especificamente no trabalho da pesquisadora Piccino $^{15}$ foi utilizada a plataforma Moodle (Modular Object-Oriented Dynamic Learning Environmen), um software livre e gratuito. O Moodle é um ambiente de aprendizagem desenvolvido pelo australiano Martin Dougiamas, em 199919. Este software oferece uma estrutura administrativa (dados cadastrais, relatório, lista de presença, calendário), acadêmica (dicas, pesquisa, disciplinas, glossário, roteiros de estudo), bem como ferramentas de interação (e-mail, chat, wiki e fórum), possibilitando uma ampla gama de canais de comunicação entre os participantes, que podem ser selecionadas pelo professor, de acordo com seus objetivos pedagógi$\cos ^{17}$. A Plataforma Moodle(1.9.19), é uma plataforma interativa de aprendizagem, disponibilizada pelo Departamento de Tecnologia Educacional da Faculdade de Odontologia de Bauru/ Universidade de São Paulo- FOB/USP e neste caso específico, foi à ferramenta escolhida para inserir o conteúdo do aprendizado à distância.

\section{Resultados}

Iniciando a apresentação dos resultados analisados considera-se importante descrever de maneira sucinta as especificidades de cada estudo relatado neste artigo para que haja compreensão de suas mensurações.

Assim, no quadro 3 é possível observar o nome do pesquisador, a produção acadêmica, as ferramentas utilizadas nas atividades presenciais e a distância, a maneira de disseminação do conhecimento feito pelos Jovens Doutores e a forma de avaliação aplicada, respectivamente. Cada produção utilizou um tema para o desenvolvimentos de seu trabalho dentro das escolas, conforme mostra o quadro. 
Quadro 3. Panorama das pesquisas analisadas

\begin{tabular}{|c|c|c|c|c|c|}
\hline Tema & $\begin{array}{l}\text { Produção } \\
\text { Acadêmica }\end{array}$ & $\begin{array}{l}\text { Atividade } \\
\text { Presencial }\end{array}$ & $\begin{array}{c}\text { Atividade } \\
\text { á } \\
\text { distancia }\end{array}$ & Disseminação & Avaliação \\
\hline Síndrome Genética ${ }^{8}$ & $\begin{array}{c}\text { Dissertação } \\
\text { de } \\
\text { Mestrado }\end{array}$ & $\begin{array}{c}\text { Tecnologias } \\
\text { de } \\
\text { Informação e } \\
\text { Comunicação }\end{array}$ & $\begin{array}{l}\text { Plataforma } \\
\text { Cybertutor }\end{array}$ & $\begin{array}{l}\text { Atividades } \\
\text { recreativas com } \\
\text { aulas } \\
\text { expositivas, } \\
\text { atividades } \\
\text { didáticas com } \\
\text { fantoches }\end{array}$ & $\begin{array}{ll}\text { - } & \text { QSP pré e } \\
& \text { pós teste } \\
\text { - } & \text { ELASI } \\
\text { - } & \text { FPM }\end{array}$ \\
\hline $\begin{array}{c}\text { Malformação de } \\
\text { orelha }^{12}\end{array}$ & $\begin{array}{c}\text { Tese } \\
\text { Doutorado }\end{array}$ & $\begin{array}{c}\text { Tecnologias } \\
\text { de } \\
\text { Informação e } \\
\text { Comunicação }\end{array}$ & $\begin{array}{l}\text { Plataforma } \\
\text { Cybertutor }\end{array}$ & $\begin{array}{c}\text { Teatro, } \\
\text { Apresentação } \\
\text { expositiva, } \\
\text { Página no } \\
\text { Facebook, } \\
\text { elaboração de } \\
\text { blog. }\end{array}$ & $\begin{array}{l}\text { - QSP pré e } \\
\text { pós teste } \\
\text { - } \quad \text { FPM }\end{array}$ \\
\hline Síndrome Genética'l & $\begin{array}{c}\text { Dissertação } \\
\text { de } \\
\text { Mestrado }\end{array}$ & $\begin{array}{c}\text { Tecnologias } \\
\text { de } \\
\text { Informação e } \\
\text { Comunicação }\end{array}$ & $\begin{array}{l}\text { Plataforma } \\
\text { Cybertutor }\end{array}$ & $\begin{array}{c}\text { Aulas } \\
\text { expositoras } \\
\text { durante evento }\end{array}$ & $\begin{array}{ll}\text { - } & \text { QSP pré e } \\
& \text { pós teste } \\
\text { - } & \text { ELASI } \\
\text { - } & \text { FPM } \\
\end{array}$ \\
\hline Saúde Auditiva ${ }^{13}$ & $\begin{array}{c}\text { Dissertação } \\
\text { de } \\
\text { Mestrado }\end{array}$ & $\begin{array}{c}\text { Tecnologias } \\
\text { de } \\
\text { Informação e } \\
\text { Comunicação }\end{array}$ & $\begin{array}{l}\text { Plataforma } \\
\text { Cybertutor }\end{array}$ & $\begin{array}{l}\text { Palestras com } \\
\text { uso de slides, } \\
\text { dinâmicas } \\
\text { interativas }\end{array}$ & $\begin{array}{ll}\text { - } & \text { QSP pré e } \\
& \text { pós teste } \\
\text { - } & \text { ELASI } \\
\text { - } & \text { FPM }\end{array}$ \\
\hline SAHOS 14 & $\begin{array}{c}\text { Dissertação } \\
\text { de } \\
\text { Mestrado }\end{array}$ & $\begin{array}{c}\text { Tecnologias } \\
\text { de } \\
\text { Informação e } \\
\text { Comunicação } \\
\text { e } \\
\text { ferramenta } \\
\text { "Homem } \\
\text { Virtual" }\end{array}$ & $\begin{array}{l}\text { Plataforma } \\
\text { Cybertutor }\end{array}$ & $\begin{array}{c}\text { Feira Cultural na } \\
\text { escola, teatro } \\
\text { de Fantoches }\end{array}$ & $\begin{array}{l}\text { - QSP pré e } \\
\text { pós teste, } \\
\text { - FPM }\end{array}$ \\
\hline $\begin{array}{l}\text { Prevenção em } \\
\text { Saúde Auditiva }{ }^{15}\end{array}$ & $\begin{array}{c}\text { Dissertação } \\
\text { de } \\
\text { Mestrado }\end{array}$ & $\begin{array}{c}\text { Tecnologias } \\
\text { de } \\
\text { Informação e } \\
\text { Comunicação } \\
\text { e } \\
\text { ferramenta } \\
\text { "Homem } \\
\text { Virtual" }\end{array}$ & $\begin{array}{l}\text { Plataforma } \\
\text { Moodle }\end{array}$ & $\begin{array}{c}\text { Feira Cultural na } \\
\text { Escola, Jornal } \\
\text { falado nas salas } \\
\text { de aula }\end{array}$ & $\begin{array}{l}\text { - QSP pré e } \\
\text { pós teste } \\
\text { - FPM }\end{array}$ \\
\hline
\end{tabular}

\section{Legendas:}

QSP: Questionário situação problema

FPM: Ficha de pesquisa motivacional

ELASI: Escala Lickert de atitudes sociais em relação à inclusão

SAHOS: Síndrome de Apneia e Hipopneia Obstrutiva do Sono 
Instrumentos de avaliação

\section{Questionários situação-problema (QSP)}

Os Questionários "Situação Problema", usados nos trabalhos foram elaborados dentro de um padrão de linguagem acessível ao nível de inteligibilidade e foram aplicados aos alunos antes da intervenção e após a intervenção. Tal estratégia foi utilizada para garantir a legitimidade da efetividade do programa e verificar a construção do conhecimento. O questionário referido foi aplicado nos estudantes das Escolas 1,2,3,4,5,6,7 para mensurar o crescimento do conhecimento dos alunos na situação pré intervenção e na situação pós intervenção.

O gráfico 1 a seguir mostra a média do crescimento do conhecimento destes alunos antes da capacitação do Projeto Jovem Doutor e após a capacitação.

Gráfico 1. Média do crescimento do conhecimento dos alunos pré e pós capacitação.

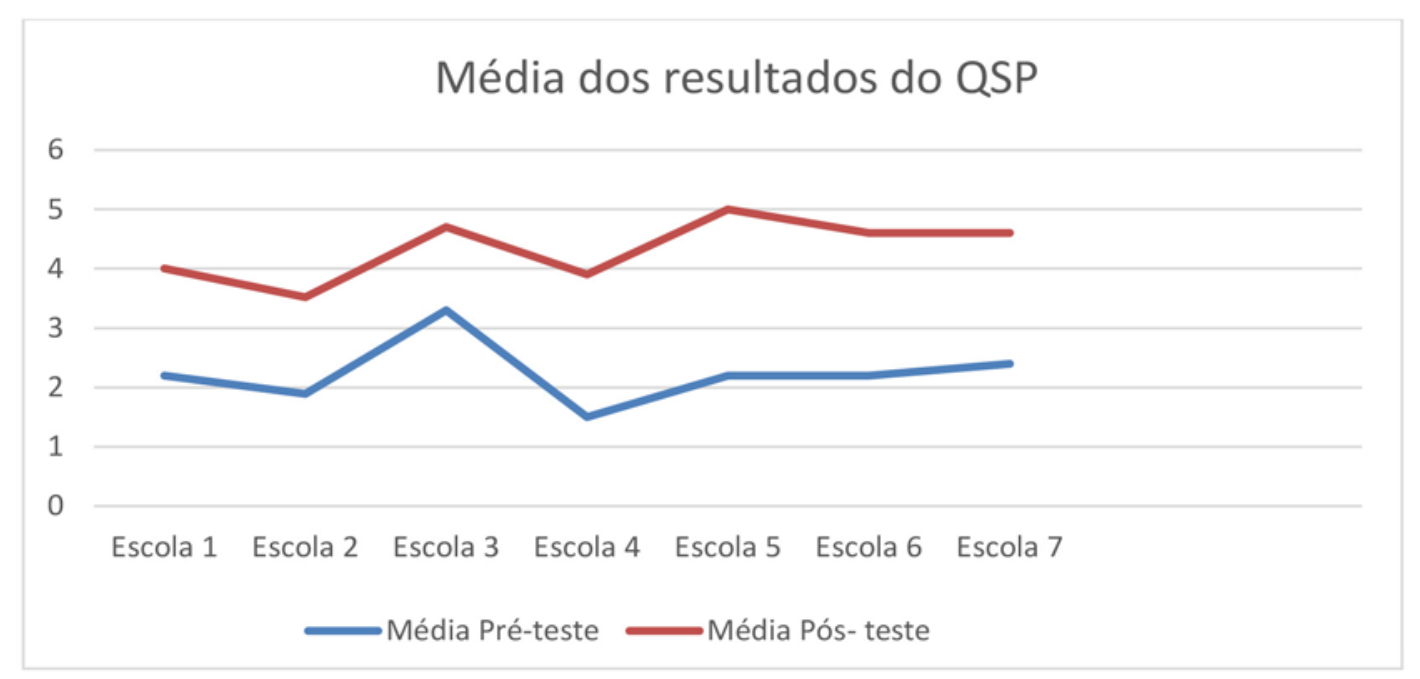

\section{Ficha de Pesquisa Motivacional (FPM)}

A Ficha de Pesquisa Motivacional (FPM) avaliou os aspectos motivacionais do acesso ao Ambiente Virtual de Aprendizagem (AVA). Foram avaliados os domínios Estimulante, Significativo, Organizado e Fácil de usar. Em todos os trabalhos 100\% dos Jovens Doutores avaliaram o curso desenvolvido no ambiente virtual, como um "Curso impressionante", com alta Expectativa pelo Sucesso nas quatro dimensões avaliadas de acordo com o proposto 20 .

\section{Escala Lickert de atitudes sociais em relação à inclusão (ELASI)}

Dentre os trabalhos referidos neste estudo, quatro pesquisadores abordaram o tema inclusão, porem somente os trabalhos das Escolas 1,3,4,5,6 e 7 , que desenvolveram o tema inclusão, aplicaram nos alunos a Escala Lickert de Atitudes Sociais em Relação a Inclusão, o ELASI. Este instrumento foi utilizado para mensurar as atitudes sociais dos alunos participantes, frente ao processo de mudança de comportamento em relação a inclusão. Tal escala foi utilizada em dois momentos, antes e após o programa de capacitação. $O$ gráfico 2 mostra a média de crescimento desta mudança de comportamento entre os estudantes. 


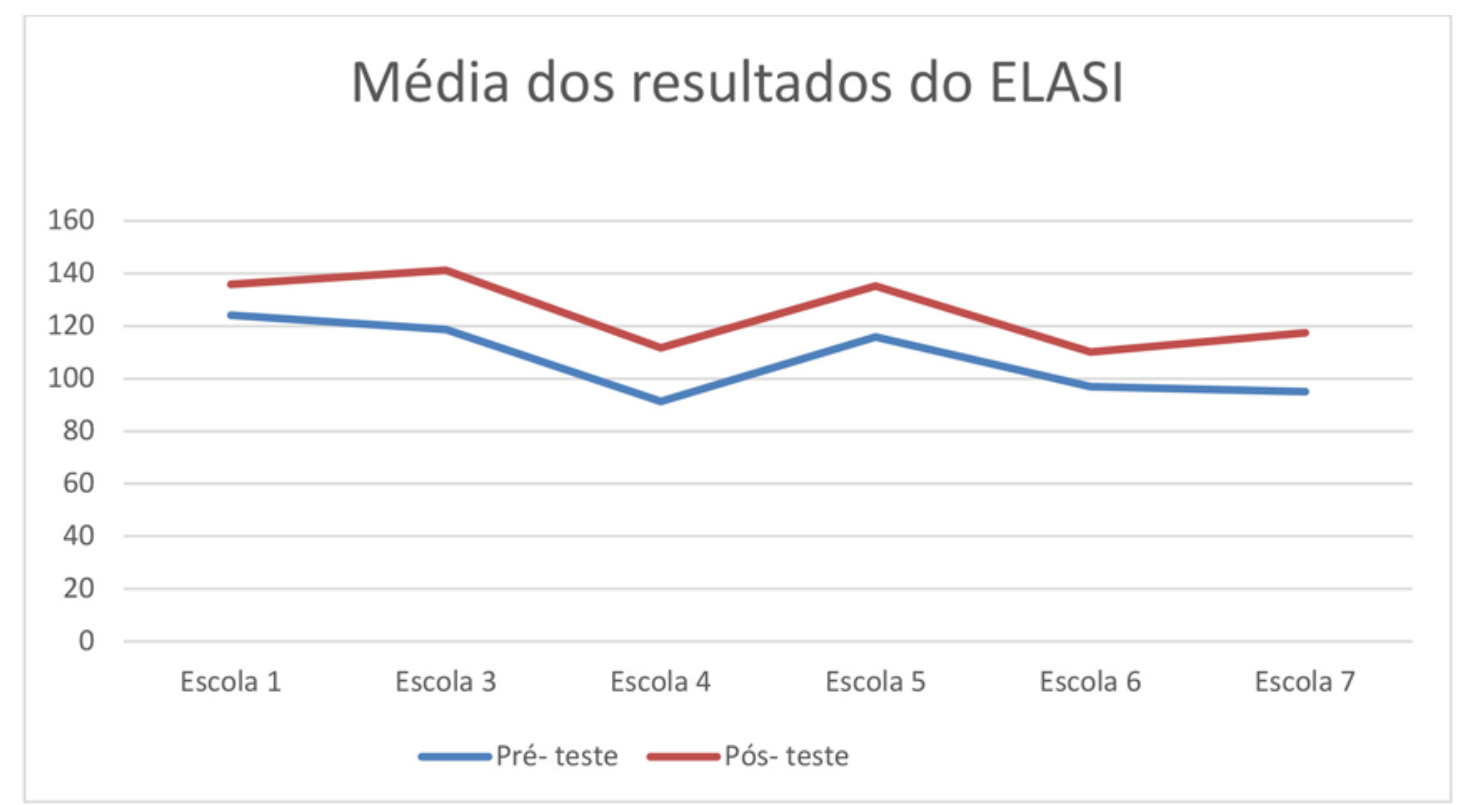

\section{Discussão}

O projeto Jovem Doutor em Bauru capacitou 90 estudantes de escolas públicas até 2015 , localizadas em comunidades carentes, sobre temas ligados a fonoaudiologia, disseminando conhecimento para mais de 2000 indivíduos, entre os alunos das escolas, professores, funcionários e comunidades envolvidas. Os recursos tecnológicos utilizados como ferramenta de aprendizado demonstraram eficácia quando analisados por meio de instrumentos de avaliação elaborados especificamente para cada projeto desenvolvido.

Dentro dos respectivos âmbitos acadêmicos, os trabalhos desenvolvidos no Projeto Jovem Doutor na área de Fonoaudiologia objetivam de maneira semelhante o desenvolvimento de modelos educacionais para a capacitação em saúde.

Com o objetivo de desenvolver e avaliar a efetividade de um programa de capacitação em Síndromes Genéticas para alunos do ensino fundamental, a pesquisadora Mirela Machado Picolini ${ }^{8}$, buscou utilizar a Teleducação Interativa para atingir seu objetivo. A proposta do trabalho da pesquisadora justifica sua importância considerando que $\circ$ banco de dados DATASUS revelou uma alta incidência de nascidos vivos com alguma anomalia genética, aproximadamente $76 \mathrm{mil}$ indivíduos, segundo o $\mathrm{Mi}$ nistério da Saúde, 2011.
Assim, diante desta realidade, fica claro a necessidade de programas educacionais para a população abrangendo a temática elegida pela pesquisadora. Os resultados demonstram a eficácia dessa forma de atuação da promoção da saúde, uma vez que a abrangência e a absorção do conhecimento pelos jovens doutores foram evidentes.

A proposta apresentada por Oliveira ${ }^{12}$ aproxima-se a de Picolini8, no que diz respeito ao tema, uma vez que esses pesquisadores também analisaram e desenvolveram um programa de capacitação em síndromes genéticas para alunos do ensino fundamental com a utilização da Teleducação Interativa. Contudo é importante ressaltar que os pesquisadores se diferenciam na especificidade do tema, considerando que Picolini 8 deu enfoque às diversas síndromes genéticas e Oliveira ${ }^{12}$ realizou a pesquisa sob a perspectiva da malformação de orelha externa ou média. Dessa forma, a abrangência, torna - Programa diversificado atingindo toda a população jovem de maneira mais ampla. As especificidades das síndromes norteiam a inclusão proposta nos estudos realizados, deixando os jovens com maior conhecimento e assim mais compreensivos. Essa perspectiva é extremamente importante diante da realidade do país que não propicia essa forma de educação da saúde. Os programas de educação, promoção e prevenção em saúde proporcionam um benefício recíproco entre a população e os sistemas de saúde do país. Além disso, os programas edu- 
cativos devem incentivar a incorporação prévia de hábitos saudáveis em crianças e adolescentes.

O trabalho de José Luiz Brito de Carvalho ${ }^{11}$, também abordou o tema inclusão. Sua casuística e metodologia se assemelham muito às pesquisas já relatadas, contudo Carvalho, desenvolveu a sua na cidade de Manaus (AM). Tal pesquisa demonstra a abrangência e a importância do ensino a distância (EAD) nos projetos de educação em saúde. O campo da saúde a EAD encontra-se entre inúmeras possibilidades metodológicas que podem ser desenvolvidas como otimizadoras da educação em saúde no Brasil. As tecnologias da informação e da comunicação possibilitam e facilitam o acesso, assim o Cybertutor foi capaz de proporcionar maior abrangência ${ }^{18}$. A EAD exerce um papel fundamental na difusão do conhecimento oferecendo acessibilidade aos que estão excluídos dos programas de saúde e do processo de educação. Diante dos resultados apresentados pelos instrumentos de avaliação, a pesquisa se mostrou eficaz, considerando que os assuntos abordados por Carvalho' ${ }^{11}$, especificamente aberrações cromossômicas, mutações gênicas, multifatoriais e craniossinostoses, contribuíram para atingir seu objetivo direcionado à inclusão social e educacional dos portadores de necessidades especiais.

A pesquisadora Falsetti ${ }^{13}$, apresentou uma importante contribuição, pois aplicou sua pesquisa em quatro escolas da rede pública de ensino, propiciando uma ampla disseminação na comunidade onde estavam localizadas as escolas. Seu estudo promoveu um alerta sobre a crescente popularização de equipamentos sonoros portáteis individuais, os quais predispõem os adolescentes a fazerem uso indiscriminado de níveis de pressão sonora elevados. Foi realizado um estudo sobre os danos auditivos provocados pelo nível de pressão sonora elevado, onde os resultados comprovaram que a maioria dos jovens não considera importante o uso de protetores auriculares em situações de intensidade sonora elevada $^{15}$. Outro importante estudo com adolescentes confirmou que os mesmos fazem uso indiscriminado de sons elevado ${ }^{15}$. Sabendo da importância sobre a falta de interesse e conhecimento dos jovens em relação aos aspectos relevantes de prevenção e cuidados com a saúde auditiva, a capacitação para este público foi extremamente importante e seus resultados demonstram que a apropriação do conhe- cimento sobre a saúde auditiva e a disseminação dessa informação foi efetiva.

Também pensando em prevenção à saúde auditiva o trabalho de Piccino ${ }^{15}$ foi eficiente e produtivo. A pesquisadora também buscou capacitar adolescentes considerando a prevenção da saúde auditiva. A disseminação deste trabalho foi particularmente abrangente, pois foi realizado um jornal falado em todas as salas do Ensino Fundamental Il e Ensino Médio e ao final os alunos participaram de uma feira cultural na escola, ou seja, a dimensão do trabalho foi grande e atingiu muitas pessoas da comunidade, uma vez que a feira fora aberta aos pais dos alunos também. $O$ mesmo ocorreu com a pesquisa de Corrêa ${ }^{14}$, que propôs a elaboração de um programa de educação voltada para a SAHOS. Destacou-se neste trabalho, como no de Piccino ${ }^{15}$, sua abrangência, pois a proposta da pesquisadora de disseminação envolveu além dos alunos capacitados, os demais alunos, pais e professores da escola através da elaboração de cartazes, pôsteres, vídeo de telejornal e peça teatral.

Projetos desenvolvido para a promoção da saúde em escolas demonstram eficácia, como no caso do Programa Sorria Bauru, advindo de uma parceria entre a Universidade do Sagrado Coração, a Universidade de São Paulo e a Universidade Paulista (Agenda USP, 2002) com a Secretaria Municipal de Saúde de Bauru, que objetivou diminuir o índice da doença cárie pelo desenvolvimento de métodos preventivos individuais e coletivos associados a práticas educativas como palestras mensais, escovação supervisionada, bochecho fluorado semanal e avaliação mensal sobre o conteúdo das palestras por meio de atividades escritas ou práticas ${ }^{22}$. Tal Programa demonstrou uma queda no índice de cárie, mostrando impacto no trabalho preventivo pela associação da prática dos bochechos com flúor e o trabalho educativo.

O método utilizado na educação em saúde demonstra sua importância também em outros projetos, como na prevenção à formação da placa bascteriana nos dentes ${ }^{23}$. Foi observada a necessidade de utilizar práticas educativas conscientizadoras e em seu trabalho, desenvolvido com 40 crianças de 8 a 10 anos, as quais foram examinadas e expostas a práticas educativas. Os autores concluem que, pela 
conscientização sobre a importância da saúde bucal na vida das pessoas, a educação em relação aos métodos preventivos e a ênfase na motivação por meio de recursos materiais e humanos, houve praticamente uma reversão do quadro inicial.

Importante ressaltar que programas de promoção à saúde no Brasil são numerosos, justamente pela realidade econômica e social do país. Contudo, cada projeto ou programa assumem caráter específico da área de atuação e o Projeto Jovem Doutor realizado na cidade de Bauru demonstra sua importância e significância diante do baixo registro de projetos na área da fonoaudiologia. Pesquisa realizada para analisar os progressos da Política de Saúde Auditiva do Brasil, levantaram expressivos dados para contribuir com estudos e planejamentos na área. Tais dados foram coletados entre os anos de 2008 e 2012 e demonstram que apesar da implantação do Programa Nacional de Atenção à Saúde Auditiva (PNASA) em 2004, a execução desse programa, quase dez anos depois, ocorre de forma desigual e ineficaz. $O$ pesquisador ainda afirma que há divergências na distribuição das unidades de saúde auditiva entre as regiões do Brasil e no interior delas, entre seus municípios, onde a maior parte dessas unidades concentra-se em áreas urbanas, dificultando 0 acesso da população de áreas periféricas ${ }^{21}$.

Assim a criação e implantação da Portaria da Saúde Auditiva em 2004 proporcionou um passo decisivo na organização de uma linha de cuidados às pessoas com deficiência de audição ou surdez, mas, a prevenção aliada a inclusão e promoção da saúde auditiva destinada à jovens é ainda baixa ou irrisória para demonstrar algum resultado ${ }^{21}$.

Dessa forma os projetos relatados são de suma importância para a conscientização da necessidade da prevenção e inclusão do deficiente nesta área da saúde. E que ações voltadas aos jovens dentro das escolas podem proporcionar mudança de comportamento e disseminação do conhecimento para a comunidade instaurando na sociedade praticas mais saudáveis, melhorando a qualidade de vida do brasileiro.

\section{Conclusão}

Aulas presenciais, dinâmicas de aprendizagem, computação gráfica e tutoria via Internet foram atividades desenvolvidas dentro da dinâmica do Projeto Jovem Doutor realizado nas escolas públicas e contribuíram para motivar e auxiliar os estudantes do ensino fundamental e médio à construção do conhecimento, e tornarem-se agentes disseminadores dos temas estudados dentro da saúde auditiva, prevenção e diagnóstico precoce de distúrbios auditivos e de comunicação, reabilitação auditiva e inclusão social de deficientes auditivos, síndromes, malformações, para a sua comunidade.

Alunos de graduação e pós-graduação, sob a orientação de professores universitários, trabalharam em conjunto com estudantes, coordenadores, professores das escolas, unidos pela mesma finalidade, promoção em saúde, aumento da qualidade de vida e desenvolvimento social.

Os programas de educação deste artigo mostram importantes estratégias, que consolidam a inclusão dos deficientes auditivos na comunidade, atitudes de prevenção e cuidado com a audição, síndromes e malformações, estimulando e motivando os participantes a realizarem a multiplicação do conhecimento, podendo, estes programas de educação serem utilizados em outras populações.

Assim, considerando que a concepção de educação em saúde está atrelada aos conceitos de educação e de saúde e que pode ser compreendida como transmissão de informações em saúde, o Programa avaliado neste estudo através dos projetos elaborados, alcança seu objetivo. Ainda é necessário pontuar que educação em saúde não pode ser reduzida apenas às atividades práticas que se reportam em transmitir informação em saúde, já que esta é considerada importante ferramenta da promoção em saúde, que necessita de uma combinação de apoios educacionais e ambientais que objetiva atingir ações e condições de vida conducentes à saú$\mathrm{de}^{10}$. Por isso, as analises descritas neste artigo convergem para este importante ponto da educação em saúde, onde ela se alia na promoção em saúde. 
Dessa forma, a proposta de inserir programa de educação em saúde nas escolas, aproveitando a obrigatoriedade da transversalidade do tema, obteve sucesso nesta avaliação.

\section{Conribuição dos autores}

Blasca WQ: Participação significativa na concepção do estudo. Envolvimento na elaboração ou revisão do manuscrito. Aprovação da versão final do manuscrito para publicação. Gomide DD: Participação na coleta de dados, ou na análise/interpretação de dados. Envolvimento na elaboração ou revisão do manuscrito. Aprovação da versão final do manuscrito para publicação. Landro ICR: Participação na coleta de dados, ou na análise/interpretação de dados. Envolvimento na elaboração ou revisão do manuscrito. Aprovação da versão final do manuscrito para publicação. Maximino LP: Orientação, participação significativa na concepção do estudo. Aprovação da versão final do manuscrito para publicação.

\section{Conflitos de interesses}

Nenhum conflito financeiro, legal ou político envolvendo terceiros (governo, empresas e fundações privadas, etc.) foi declarado para nenhum aspecto do trabalho submetido (incluindo mas não limitandose a subvenções e financiamentos, conselho consultivo, desenho de estudo, preparação de manuscrito, análise estatística, etc).

\section{Referências}

1. Brasil. Secretaria de Educação Fundamental. Parâmetros curriculares nacionais: introdução aos parâmetros curriculares nacionais / Secretaria de Educação Fundamental. Brasília: $\mathrm{MEC} / \mathrm{SEF} ; 1997$.

2. Pan American Health Organization Health in the Americas: 2012 Edition. Saúde nas Américas: Panorama Regional e perfis de países [Internet]. [acessado em 2015 dez. 07]. Disponível em: http://www.paho.org/saludenlasamericas/ index.php?option $=$ com_docman\&task $=$ doc view\&gid $=1$ 18\&ltemid $=$

3. Focesi E. Educaçäo em saúde na escola, o papel do professor. Rev bras Saúde esc. 1990;1(2):4-8.

4. Gouvêa LAVN. Educação para Saúde na Legislação Educacional no Brasil. In: Seminário Nacional: Estado e Políticas Sociais no Brasil, 2007, Cascavel, Paraná. Unioeste, 2007.

5. Brasil. Conselho Federal de Educação. Parecer $n^{\circ}$ 2.264/74. Programas de saúde: educação da saúde. Rio de Janeiro: Editex, 1974.
6. Mohr A, Venturi T. Fundamentos e objetivos da Educação em Saúde na escola: contribuições do conceito de alfabetização científica. Atas do $9^{\circ}$ Congreso Internacional sobre Investigación en Didáctica de las Ciencias, Girona, Espanha; 2013.

7. Wen CL. Modelo de ambulatório virtual (Cyberambulatório) e tutor eletrônico (Cybertutor) para aplicação na interconsulta médica, e educação à distância mediada por tecnologia [tese]. São Paulo: Faculdade de Medicina da USP; 2013.

8. Picolini MM. Teleducação interativa na capacitação de estudantes do ensino fundamental em síndromes genéticas [dissertação]. Bauru: Faculdade de Odontologia de Bauru, Universidade de São Paulo; 2011.

9. Chao LW . Considerações sobre o Jovem Doutor [Internet]. [acesso em 2018 mar. 05]. Disponível em: http://jovemdoutor. org.br/programa/consideracoes-sobre-o-jovem-doutor/

10. Blasca WQ, Correa C, Zabeu JS, Picolini MM, PardoFanton CS, Silva ASC et al. Projeto Jovem Doutor em processos e distúrbios da comunicação: Educação interativa para a formação de rede colaborativa de saúde. In: Anais XIX Jornada Fonoaudiológica de Bauru "Profa. Dra. Katia Flores Genaro", 2012, Bauru-SP.

11. Carvalho JLB. Promoção da saúde em ensino fundamental: ações de teleducação em Fonoaudiologia na inclusão escolar [dissertação]. Bauru: Faculdade de Odontologia de Bauru, Universidade de São Paulo; 2012.

12. Oliveira VV. Jovem doutor: promoção da saúde auditiva e inclusão do deficiente auditivo com malformação de orelha externa e/ou média [tese]. Bauru: Hospital de Reabilitação de Anomalias Craniofaciais, Universidade de São Paulo; 2012.

13. Falsetti APM. Rede de aprendizagem colaborativa de educação em saúde auditiva. [dissertação]. Bauru: Faculdade de Odontologia de Bauru, Universidade de São Paulo; 2013.

14. Corrêa CC. Projeto Jovem Doutor: ações de educação em saúde voltadas à síndrome da apnéia e hipopnéia obstrutiva do sono [dissertação]. Bauru: Faculdade de Odontologia de Bauru, Universidade de São Paulo; 2014.

15. Piccino MTRF. Modelo educacional interativo para adolescentes usuários de fones de ouvido [dissertação]. Bauru: Faculdade de Odontologia de Bauru, Universidade de São Paulo; 2015.

16. Omote S. Construção de uma escala de atitudes sociais em relação à inclusão: notas preliminares. Rev Bras Ed Esp. $2005 ; 11(1): 33-48$. 
17. Blasca WQ. Una estrategia de teleducación sobre la salud auditiva y vocal en Brasil. Revista de Logopedia, Foniatría y Audiología (Ed. Impresa). 2014;35(1):2-7.

18. Soirefmann M, Boza JC, Comparin C, Cestari TF, Wen CL. Cybertutor: um objeto de ensino na Dermatologia. An Bras Dermatol. 2010;85(3):400-2. doi: 10.1590/S0365$\underline{05962010000300021}$

19. Santos JRL. A utilização da plataforma Moodle numa escola básica: realidade ou ficção na inserção das TIC em sala de aula [dissertação]. Lisboa: Universidade Aberta; 2010.

20. Paixão MP. Modelo de educação a distância em hanseníase voltado para a rede de detecção de casos e diagnósticos [tese]. São Paulo: Faculdade de Medicina, Universidade de São Paulo; 2008.

21. CL Andrade, L Fernandes, HE Ramos, CMC Mendes, CAD Alves. Programa Nacional de Atenção à Saúde Auditiva: avanços e entraves da saúde auditiva no Brasil. Rev Ciênc Méd Biol. ISSN 1677-5090. 2013;12(4):404-410.

22. Pauleto ARC, Pereira MLT, Cyrino EG. Saúde bucal: uma revisão crítica sobre programações educativas para escolares. Revista Ciência e Saúde Coletiva. 2004;9(1):21 130. doi: $10.1590 /$ S1413-81232004000100012

23. Gomes AS, Gianlup EM, Abreu CB. A importância da conscientização e da prática preventiva em odontologia. Revista Odontologia e Ciência. 1993;8(16):115-125. 